\title{
Study on Valve Strategy and Fuel Benefits of Skip Fire Based on Electromagnetic Valve Train
}

\author{
Maoyang Hu and Siqin Chang \\ Nanjing University of Science and Technology, 210094 Nanjing, China
}

\begin{abstract}
Cylinder deactivation (CDA) is a fuel consumption reduction technology for gasoline engines. Skip fire is a new type of CDA because the load and the density of firing cylinder are in proportion to the torque demand. However, it is difficult to realize because valves need to be switched between valve deactivation and normal operation stroke by stroke. The Electromagnetic valve train (EMVT) provides a fully flexible control method to achieve skip fire. In the paper, a new skip fire strategy based on electromagnetic intake valve train (EMIV) is proposed. Then, the oxygen concentration of the exhaust pipe, energy losses, in-cylinder pressure of the skipped cycle and exhaust gas recirculation (EGR) rate of the firing cycle are studied by the 1D simulation in GT-Power. The results shows the majority of gas sucked into the skipped cylinder is exhaust gas by reasonable control of IVO and IVC, and the exhaust oxygen-rich can be avoided. Meanwhile, EGR rate of the firing cylinder and energy losses of the skipped cylinder are maintained at lower level. At the conditions of 1200 and $1600 \mathrm{rpm}$, fuel economy has been improved respectively $8.1 \%-16.6 \%$ and $6.4 \%-14.6 \%$ when the brake mean effective pressure (BMEP) ranges from $0.4 \mathrm{MPa}$ to $0.2 \mathrm{MPa}$.
\end{abstract}

\section{Introduction}

Due to the restriction of the air flow into the cylinders by the throttle, the pumping mean effective pressure (PMEP) is large at part load conditions for throttled internal combustion engines. The possible solution to this problem is to adopt early or late intake valve closing (EIVC or LIVC) strategy [1-3]. Additionally, the most widely used way to improve the part load efficiency is the utilization of downsizing in combination with turbocharging. Besides, CDA has been demonstrated as a reliable technology to improve fuel economy in gasoline engines. The pumping losses are reduced due to higher intake manifold pressure [4,5], and combustion is generally more complete with larger air-fuel charge motion. The majority of CDA systems are used on multicylinder and large displacement engines. The skip fire strategy is a new type of variable displacement. Compared with traditional CDA, the greatest advantage of skip fire strategy is that the load and the density of firing cylinder are in proportion to the torque demand. So the firing cylinders can work in the high efficiency area, and the heat and mechanical balance of all cylinders are consistent. However, it is difficult to realize skip fire strategy because the cylinder switches frequently between skip cycle and firing cycle, requiring the valves to be controlled stroke by stroke to transform between valve deactivation and normal operation. The skip fire strategy can be achieved by simply interrupting fuel injection and ignition in the skipped cylinders [6,7]. But the air is sucked into the skipped cylinder and then discharged into the exhaust pipe, leading to the exhaust oxygen-rich. Chien et al. [8] studied the skip fire based on a $6.2 \mathrm{~L}$ engine with modified valve train. When a skip event is desired, the intake valve and the exhaust valve are deactivated. But the minimum in-cylinder pressure of skipped cycles is about $0.006 \mathrm{MPa}$ that may lead to oil being drawn in cylinder, even if the decrease of trapped exhaust gas is beneficial to reduce the air spring losses [9]. Millo et al. [10] proposed a fixed CDA mode strategy based on MultiAir system. They studied the pumping losses and oxygen concentration in the exhaust line, and got the optimal intake valve closing timing. But the minimum pressure of inactive cylinder wasn't mentioned and they didn't study the effects of intake valve opening on pumping losses and oxygen concentration.

This paper focuses on valve strategy of skip fire strategy based on EMIV. Besides, oxygen concentration of the exhaust pipe, the energy losses and the minimum in-cylinder pressure of skipped cycle are studied by the 1D simulation. Lastly, the fuel economy benefits are also analyzed at low load conditions.

\section{Valve strategy and model details}

\subsection{Valve strategy}

Self-developed EMVT is a highly flexible camless valve train system that offers flexible variable valve timing, 
valve duration and valve lift $[11,12]$, which provides a feasible approach to actualize skip fire strategy. It has been proved that EMVT has large potential for improving engine performances, such as charge motion control, variable compression ratio, as well as variable displacement $[9,13,14]$. Some of these attributes are unique to EMVT. Fig. 1 shows the EMVT installed at the intake side without any modification for the exhaust system, and the test bench of engine cylinder head with EMIV has been completed.

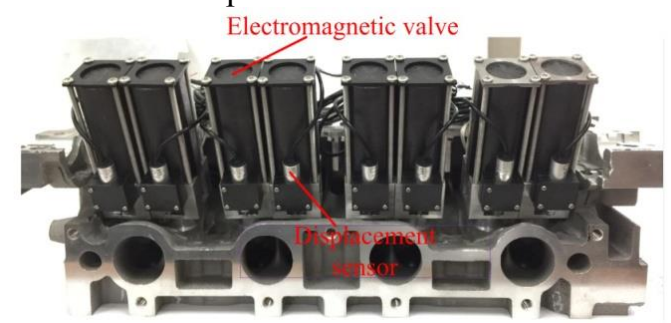

Figure 1. Test bench of engine cylinder head with EMVT.

In order to achieve skip fire operation, here we propose three requirements below. Firstly, current production CDA systems usually introduce exhaust gas or fresh air in deactivated cylinder to keep the minimum in-cylinder pressure above a certain limit. Gottschalk et al. [15] investigated CDA based on a variable valve train and adopted $0.02 \mathrm{MPa}$ as the minimum in-cylinder pressure limit to prevent the piston rings from a failure. In this paper, we set the value of $0.02 \mathrm{MPa}$ as the minimum in-cylinder pressure limit. Secondly, the exhaust oxygen-rich would cause the efficiency of threeway catalytic converter decreasing. The additional fuel is injected to keep the average air-fuel ratio at the stoichiometric value, which depresses fuel economy achieved by skip fire. So valve strategy needs to ensure that the oxygen concentration in exhaust pipe had better be less than $1 \%$ according to Millo's study [10]. Thirdly, the requirement of avoiding interference between valve and piston is not necessary for an engine because of different geometry sizes. As for the $1.8 \mathrm{~L}$ prototype engine of the paper, in order to avoid collision between valve and piston, the maximum allowable valve lift should be no more than $4 \mathrm{~mm}$ at top dead center (TDC) based on the measurement data.

As a matter of fact, fresh air or exhaust gas is usually trapped into the deactivated cylinder for the CDA system. As for the valve strategy of skip fire achieved by EMIV, only exhaust gas can be trapped into skipped cycle because fresh air of skipped cycle would cause exhaust oxygen-rich when the exhaust valve opens during the exhaust stroke of skipped cycle. The exhaust gas of the firing cycle would be discharged into the exhaust pipe, so the only way is that exhaust gas is firstly pressed into the intake manifold by opening intake valve during the exhaust stroke of skipped cycle and then is sucked into the cylinder. According to the above requirements and analysis, a new valve strategy with EMIV is proposed to realize skip fire without any modification for the exhaust valves, as shown in Fig. 2. In the condition of skip fire, the exhaust valve is always active. During the exhaust stroke of firing cycle, the intake valve opens until intake stroke of skipped cycle. Some exhaust gas is firstly pressed into the intake manifold before $360 \mathrm{CA}$, and then sucked into the cylinder together with a small amount of fresh air during intake stroke of skipped cycle. Lastly, the trapped gas is discharged into the exhaust pipe in the exhaust stroke of skipped cycle. As to be seen, the more fresh air sucked into the cylinder, the higher oxygen concentration in the exhaust. The main purpose of this paper is to analyze the variations of the oxygen concentration, as well as other performances of skip fire.

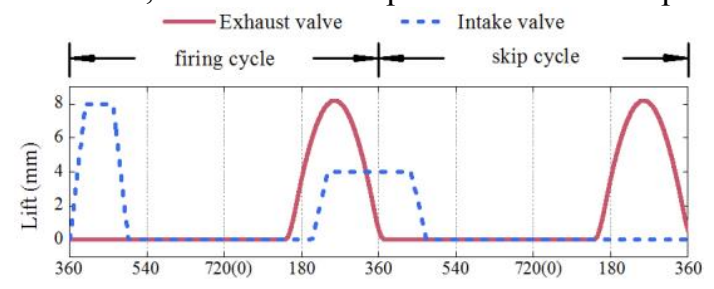

Figure 2. The schematic diagram of the valve strategy with EMIV.

\subsection{Model details}

One dimensional model of the four-cylinder gasoline engine is carried out in GT-Power while the main characters of the prototype are listed in Table 1.

Table 1. Engine specifications

\begin{tabular}{|c|c|}
\hline Feature & Value \\
\hline Displacement & $1.8 \mathrm{~L}$ \\
\hline Stroke/Bore & $89.3 \mathrm{~mm} / 80 \mathrm{~mm}$ \\
\hline Connecting rod & $133.1 \mathrm{~mm}$ \\
\hline Compression ratio & 10.5 \\
\hline Rated power & $95.7 \mathrm{~kW} @ 6000 \mathrm{r} / \mathrm{min}$ \\
\hline Rated torque & $171.3 \mathrm{~N} \cdot \mathrm{m} @ 4500 \mathrm{r} / \mathrm{min}$ \\
\hline
\end{tabular}

In simulation model, WoschniGT model is chosen to simulate the heat transfer processes, and the formula is shown as below.

$$
h_{c}=3.26 B^{-0.2} p^{0.8} T^{0.55} w^{0.8}
$$

Where $h_{c}$ the heat-transfer coefficient, $B$ is the bore of cylinder, $p$ is the instantaneous cylinder pressure, $T$ is the mean cylinder gas temperature, $w$ is the average cylinder gas velocity. The engine friction is calculated using Chen-Flynn friction model, as shown in equation 2.

$$
F M E P=F M E P_{\text {Const }}+A P_{C y l . m a x}+B c_{p . m}+C c_{p . m}^{2}
$$

Where $F M E P_{\text {Const }}$ is the constant part of FMEP; $A$ is the peak cylinder pressure factor; $B$ is the mean piston speed factor; $C$ is the mean piston speed squared factor; $P_{C y l \text { max }}$ is maximum cylinder pressure; $c_{p . m}$ is the mean piston speed. Accuracy of this model is validated by the experiments of prototype engine, as shown in Fig. 3. Data analyses demonstrate that the model can make the 
predictions about the torque and fuel consumption with the errors less than $3 \%$. In order to analyze proposed valve strategy with EMIV, an EMIV engine model needs to be established. In GT-Power, the valve train of prototype engine model is replaced by the template called ValveSolSignalConn that is controlled via a logic signal ( 0 or 1$)$. The valve will start opening or closing when the control signal switches between 0 and 1 , which provides a method to simulate EMIV engine and research skip fire valve strategy.

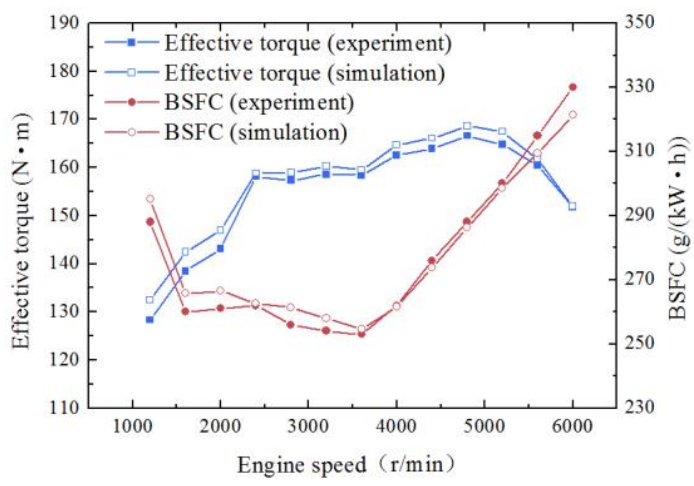

Figure 3. Comparisons of simulated results and experimental results for prototype engine.

\section{Results analysis}

\subsection{Pressure characteristics of skipped cylinder}

Fig. 4 shows the in-cylinder pressure of two cycles including one firing cycle and one skipped cycle. It is visible that the minimum pressure during skipped cycle is greater than $0.2 \mathrm{MPa}$ caused by some exhaust gas sucked into skipped cycle, which avoids the possibility of oil suction. Thereby the minimum pressure is related to the intake valve timing.

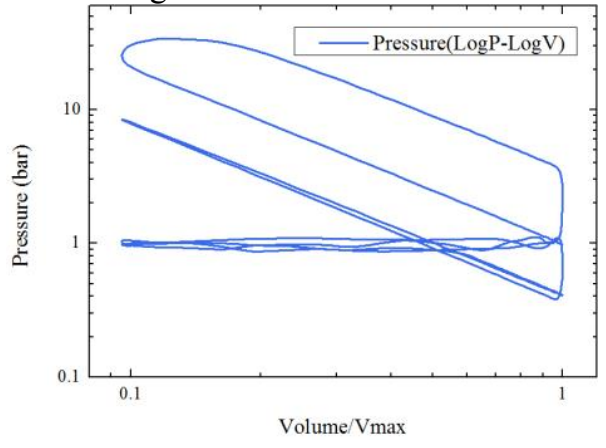

Figure 4. The pressure of one firing cycle and one skipped cycle.

Fig. 5 shows the minimum in-cylinder pressure of the skipped cycle at different IVO and IVC When the IMEP360 of the firing cycle is $0.786 \mathrm{MPa}$ at $1600 \mathrm{rpm}$. The minimum in-cylinder pressure of the skipped cycle is proportional to the mass of the exhaust gas trapped in the cylinder. The later the intake valve closes, the higher incylinder pressure is. And the intake valve needs to close after $418 \mathrm{CA}$ to ensure that the minimum pressure is greater than $0.02 \mathrm{MPa}$. It is necessary to explain that the intake valve closing time can't be earlier than 420CA when intake valve opens at $180 \mathrm{CA}$, because more exhaust gas may be trapped in intake manifold resulting in insufficient fresh air of next firing cycle and deteriorating combustion.

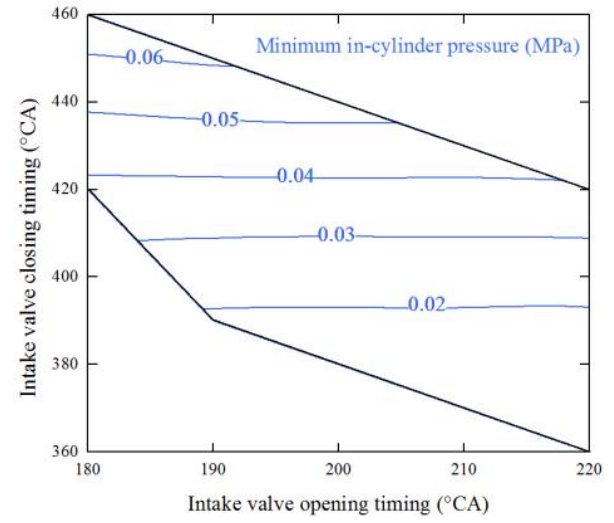

Figure 5. The minimum in-cylinder pressure of the skipped cycle at different IVO and IVC.

\subsection{Oxygen concentration and EGR rate}

The oxygen concentration in the exhaust pipe and the EGR rate of the firing cycle at different IVC are illustrated in Fig. 6 when the intake valve opens at 180CA. As to be seen, the oxygen concentration increases little with the delay of IVC before 430CA, because most gas sucked into the skipped cycle is exhaust gas and the corresponding residual exhaust gas in the intake manifold reduced rapidly resulting in a sharp decline in the EGR rate of the firing cycle. After 430CA, the oxygen concentration increases rapidly because the exhaust gas remained in the intake manifold becomes less and less, leading to a large number of fresh air being sucked into the cylinder. Correspondingly, the EGR rate of the firing cycle also gradually reduced to a stable value. From the above analysis, the components of gas sucked into skipped cycle are affected by the IVO and IVC. In addition, the EGR rate of the firing cycle, the energy losses and the minimum in-cylinder pressure of the skipped cycle also change with the IVO and IVC.

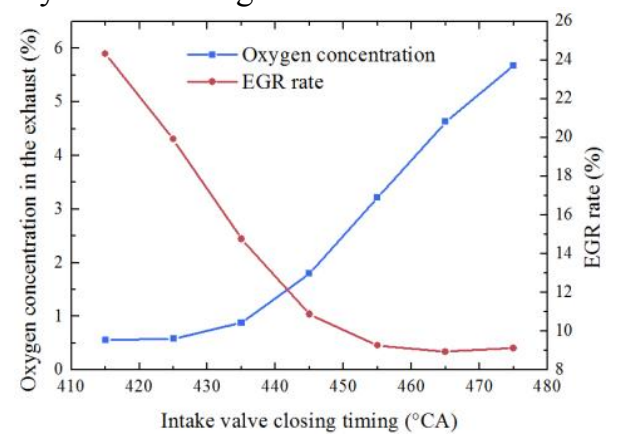

Figure 6. The oxygen concentration in the exhaust pipe and the EGR rate of the firing cycle.

Fig. 7 shows the oxygen concentration in the exhaust pipe and the EGR rate of the firing cycle at different IVO and IVC. The trend of the oxygen concentration and the EGR rate is completely opposite. At a giving IVO, advancing IVC helps to reduce oxygen concentration. The exhaust gas, in combination with, the fresh air in the intake manifold is gradually sucked into the cylinder with 
the IVC delayed, which cause a rapid increase of the oxygen concentration in the exhaust pipe. Correspondingly, the EGR rate of the firing cycle also drops rapidly.

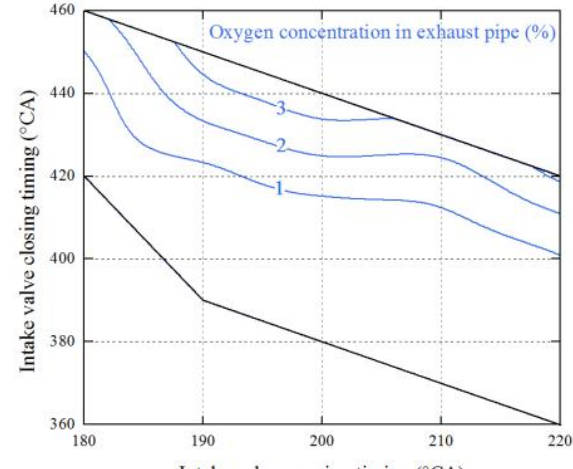

Intake valve opening timing $\left({ }^{\circ} \mathrm{CA}\right)$

(a) oxygen concentration

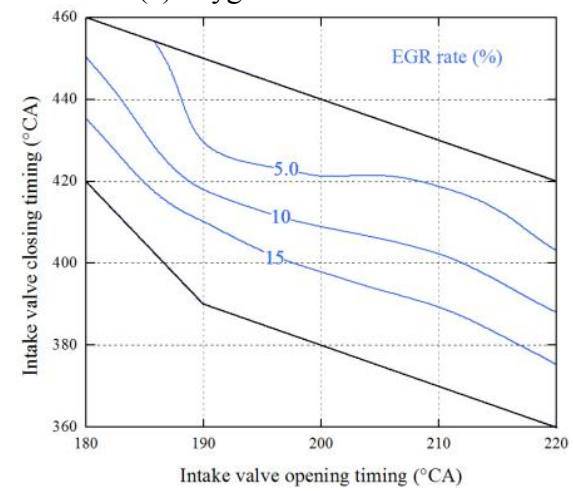

(b) EGR rate

Figure 7. The oxygen concentration and the EGR rate.

\subsection{Energy losses of skipped cylinder}

Fig. 8 shows the total energy losses of three periods including gas exchange from exhaust stroke of the firing cycle to intake stroke of the skipped cycle, two-stroke compression expansion process of the skipped cycle and gas exchange process from exhaust stroke of the skipped cycle to intake stroke of the firing cycle. It can be obtained that advancing IVO and delaying IVC are beneficial to reduce the total energy losses.

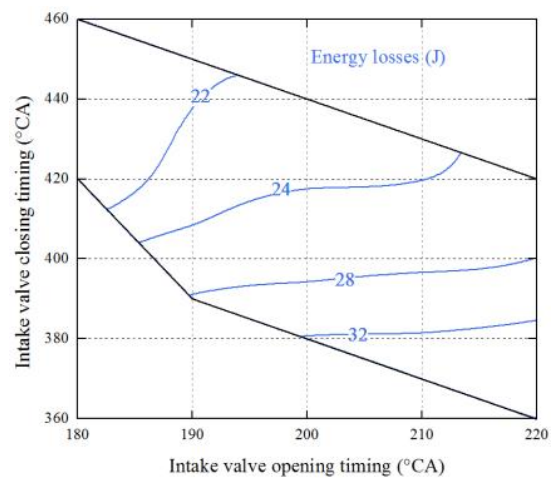

Figure 8. The total energy losses of three periods.

The optimal IVO and IVC of the proposed valve strategy are influenced by oxygen concentration, incylinder pressure and energy losses. The oxygen concentration in the exhaust pipe and the minimum in- cylinder pressure of skipped cylinder should be lower than $1 \%$ and $0.02 \mathrm{MPa}$ respectively. Besides, the EGR rate should not be too high and the energy losses had better be reduced as much as possible. For this operating condition, it is finally confirmed that the intake valve opens at 180CA and closes at 440CA. The oxygen concentration in the exhaust pipe is about $0.6 \%$. The EGR rate of the firing cycle is $13.23 \%$ and energy losses are about $19.75 \mathrm{~J}$.

\subsection{Fuel economy}

Through the above analysis, the optimal IVO and IVC can be obtained when the firing cycles work in different loads and speeds. The FMEP, PMEP and fuel economy achieved by the skip fire strategy based on EMIV are illustrated in Fig. 9. The FMEP has no evident differences, while the PMEP of skip fire condition is reduced obviously compared with that of prototype, which makes the greatest contribution to fuel economy. At low load condition, skip fire strategy significantly improves fuel economy. At 1200 and $1600 \mathrm{rpm}$, skip fire strategy respectively provides $8.1 \%-16.6 \%$ and $6.4 \%$ $14.6 \%$ reductions on BSFC compared with the prototype engine when the BMEP ranges from 0.4MPa to $0.2 \mathrm{MPa}$.

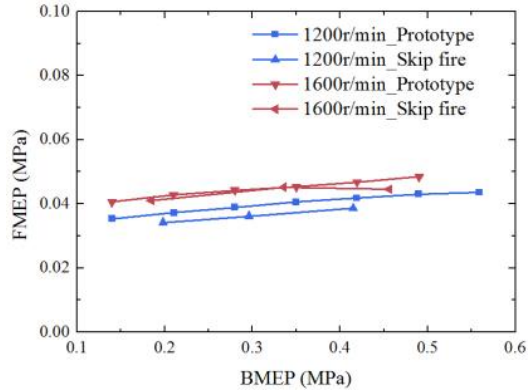

(a) FMEP

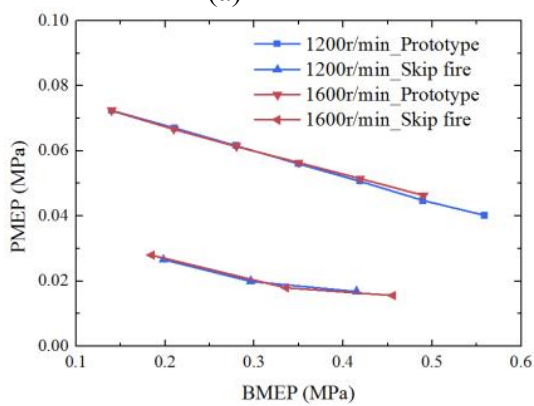

(b) PMEP

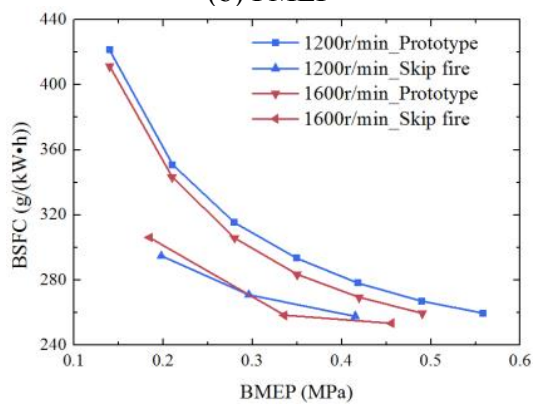

(c) Fuel economy benefits

Figure 9. The FMEP, PMEP and fuel economy of skip fire strategy. 


\section{Conclusion}

A new valve strategy with EMIV is proposed to realize skip fire without any modification for the exhaust valves. By the 1D simulation in GT-Power, main results are summarized as followed.

(1) In skip fire operation, it can be realized that the majority of gas sucked into the cylinder of the skipped cycle is the exhaust gas resulting from reasonable control of IVO and IVC, and exhaust oxygen-rich is avoided.

(2) Advancing IVO and delaying IVC are beneficial to reduce energy losses of skipped cycle and increase the amount of gas trapped in the skipped cycle. The latter helps to raises the in-cylinder pressure of the skipped cycle and avoids the risk of oil suction.

(3) For the condition of $1600 \mathrm{rpm}$ with $0.786 \mathrm{MPa}$ IMEP360, the IVO and IVC of the proposed valve strategy are confirmed about 180CA and 440CA respectively. The oxygen concentration in the exhaust pipe and the minimum in-cylinder pressure of skipped cylinder are lower than $1 \%$ and $0.02 \mathrm{MPa}$ respectively. The EGR rate and energy losses are maintained at a lower level.

(4) For the skip fire operation, the reduction of PMEP makes the greatest contribution to fuel economy. At 1200 and $1600 \mathrm{rpm}$, fuel economy has been improved respectively $8.1 \%-16.6 \%$ and $6.4 \%-14.6 \%$ when the BMEP ranges from $0.4 \mathrm{MPa}$ to $0.2 \mathrm{MPa}$.

(5) The test of EMVT engine has encountered great challenges. Nowadays we are actively solving EMVT engine test problems in order to verify the simulation in the paper.

\section{References}

1. T. Li, Y. Gao, J. Wang, Z. Chen, Energ. Convers. Manage 79, 59-65 (2014)

2. T. Tomoda, T. Ogawa, H. Ohki, T. Kogo, K. Nakatani, E. Hashimoto, Int. J. Engine. Res 11(5), 331-344 (2010)

3. F. Millo, S. Luisi, F. Borean, A. Stroppiana, Fuel 121, 298-310 (2014)

4. M. Wilcutts, J. Switkes, M. Shost, A. Tripathi, SAE. Int. J. Engines 6, 278-288 (2013)

5. M. Abas, R. Martinez-Botas, SAE Technical Paper, 2015-01-0983 (2015)

6. Y. Zhao, B. Zhou, U.S. Patent Application No. 12/550,056 (2010)

7. L. Yüksek, O. Özener, T. Sandalcı, Energ. Convers. Manage 64, 320-327 (2012)

8. L.C. Chien, M. Younkins, M. Wilcutts, SAE Technical Paper, 2015-01-1717 (2015)

9. M. Hu, S. Chang, L. Liu, Y. Xu, J. Xu, Appl. Therm. Eng 129, 833-840 (2018)

10. F. Millo, M. Mirzaeian, S. Luisi, V. Doria, A. Stroppiana, Fuel 180, 645-652 (2016)

11. L. Liu, S. Chang, P. I. Mech. Eng. D. J. Aut 226(1), 85-93 (2012)

12. L. Liu, S. Chang, Mechatronics 21(7), 1234-1238 (2011)

13. J. Xu, S. Chang, X. Fan, A. Fan, Appl. Therm. Eng 96, 708-715 (2016)

14. X. Fan, S. Chang, L. Liu, J. Lu, Appl. Therm. Eng 112, 371-377 (2017)

15. W. Gottschalk, R. Fink, M. Schultalbers, SAE Technical Paper, 2016-01-2346 (2016) 